\title{
Um objeto fugidio: \\ voz e "musicologias"
}

\section{Elizabeth Travassos* \\ Universidade do Rio de Janeiro (UNIRIO)}

\section{Resumo:}

Componente indissociável da fala e do canto, a voz é um objeto fugidio que escapa às abordagens parciais das várias disciplinas que dela se ocupam. A partir desta constatação, discuto o lugar da voz nos saberes sobre a música. As tipologias vocais geradas no canto erudito, comprometidas com as técnicas e estéticas desenvolvidas na Europa, modernamente, não são extensivas às vocalizaçōes populares e folclóricas. As análises musicais que privilegiam o eixo sintático da música também dizem pouco sobre a voz. Revejo, então, alguns aspectos da "cantométrica" de Alan Lomax, metodologia que - juntamente com as etnografias da fala e da música - constitui um avanço na integração de fonética, antropologia e musicologia.

Palavras-chave: voz; qualidade vocal; cantométrica

*Elizabeth Travassos é Doutora em Antropologia pelo Programa de Pós-Graduaçāo em Antropologia Social do Museu Nacional (UFRJ). Leciona antropologia e etnomusicologia no Instituto Villa-Lobos e no Programa de Pós-graduaçāo em Música da UNIRIO. É Pesquisadora do CNPq. Publicou Os mandarins milagrosos: arte e etnografia em Mário de Andrade e Béla Bartók (1997) e Modernismo e música brasileira (1999). Organizou o volume sobre arte e cultura popular da Revista do Patrimônio (IPHAN, 1999) e. com José Alberto Salgado e Silva, o número 8 de Debates: Cadernos da Pós-graduação em Música (UNIRIO, 2005). Com Cláudia Matos e Fernanda Teixeira de Medeiros, organizou a coletânea Ao encontro da palavra cantada: poesia. música, voz (2001). 
Embora os fenômenos humanos [...] possam ser examinados em si, independentemente de suas ligacooes com a vida social, eles, por natureza, nada mais são do que concretizações de relações e comportamentos, materializações da vida social e mental. Isto se aplica à fala, que nada mais é que relações humanas transformadas em som...

Norbert Elias (O processo civilizador)

\section{Introdução'}

Num ensaio recente, o etnomusicólogo Gary Tomlinson (2003) discute o processo histórico que resultou na distribuição de objetos entre disciplinas musicológicas e dá pistas para pensarmos o lugar que ocupam a voz e o canto nos saberes sobre a música. Vejamos seu argumento. O divórcio entre musicologia dedicada sobretudo à música escrita do passado - e etnomusicologia - dedicada sobretudo às músicas das populaçōes "primitivas" e folk - reproduz, no plano da ciência, as oposições homólogas entre "nós" e "eles", entre "a" música e "outras" músicas, entre o estudo do texto e o do contexto, entre objeto autônomo e prática heterônoma, entre mudança e estase. Essa divisão, segundo o autor, não pode ser compreendida independentemente do processo que culminou, no século XIX, na consagração da noção de música "pura", "abstrata", representada pela música instrumental (tal como conhecida na Europa). Não obstante o prestígio de que haviam desfrutado os repertórios vocais nesse mesmo universo cultural europeu, principalmente os gêneros sacros e a ópera, a música instrumental acedeu então à condição de representante da "abstração".

$O$ advento dessa categoria deslocou o foco do pensamento sobre a música que, ao longo do século XVIII, havia tomado o canto como paradigma da expressão musical, comum a civilizados e selvagens: "Um impulso musicológico (ou melhor, cantológico [...]) mais antigo - diz Tomlinson - precede a emergência completa das formas modernas historiográficas e etnográficas." (2003, p. 33).

\footnotetext{
${ }^{1}$ Este artigo tem origem na palestra que preparei para o II Encontro de Estudos da Palavra Cantada (Rio de Janeiro, maio de 2006) e na conferência de encerramento do III Simpósio de Música da Universidade Federal do Paraná (Curitiba, novembro de 2006).
} 
Plenamente comensuráveis, o canto selvagem e o canto refinado do século XVIII eram exemplares da mesma capacidade expressiva, nos textos de pensadores como Vico e Rousseau. A unidade rompeu-se com a elevação da música instrumental à categoria "música abstrata". O argumento de G. Tomlinson, sintetizado nesta introdução, corrobora a suspeita de que a posição relativamente marginal da voz e do canto na musicologia deita raízes no processo de constituição mesma da noção de música erudita.

Além do alheamento recíproco entre os múltiplos saberes que têm a voz como objeto, ele é de difícil tratamento quando se adota certa modalidade de abordagem musicológica. Na condição de totalidade bio-psicossocial (Mauss, 1974 [1905]), a voz escapa às apreensões parciais das várias disciplinas e técnicas que dela se ocupam: fonética, literatura oral, fisiologia da voz, acústica musical, canto, etnomusicologia, fonoaudiologia, psicanálise... Esta situação liminar foi percebida por outros pesquisadores. José Roberto do Carmo Jr. (2003), por exemplo, observa que a fisiologia da voz e a fonética articulatória se ocupam da produção do som vocal, mas não do sentido; a lingüística trata da linguagem verbal, mas não do canto, e somente incorpora distinções de altura, intensidade e duração sob a rubrica da prosódia, na forma "retraída" em que aparecem na fala.

16 Segundo a síntese de Paul Zumthor:

É estranho que, entre todas as nossas disciplinas instituídas, não haja ainda uma ciência da voz. Esperemos que ela se forme em breve: ela traria para o estudo da poesia oral uma base teórica que lhe falta. Abarcaria, para além de uma física e de uma fisiologia, uma linguística, uma antropologia e uma história. (1997, p. 11).

Tendo como ponto de partida estas constataçōes, dou início, neste artigo, a uma discussão do lugar da voz nos saberes sobre a música. Em seguida, revejo alguns aspectos da cantométrica (de Alan Lomax) e das etnografias da fala e da música, que desenvolveram métodos e noções importantes, às quais talvez se possa integrar os conhecimentos gerados nos estudos de fonética e acústica. 


\section{Uma musicologia da voz?}

Falar da voz como um objeto fugidio é reiterar uma impressão compartilhada por vários autores. Se a repito, é para assinalar a carência de terminologia analítica consensual e aplicável à heterogeneidade de estilos vocais "populares" e "folclóricos", no Brasil. ${ }^{2}$ Como professora de etnomusicologia, levo à sala de aula gravaçōes sonoras de repentes e romances, folias de reis, benditos, calangos e outros gêneros da tradição oral brasileira. Aprendi a não subestimar o estranhamento que produzem os sons nasais e metálicos, a voz que "quebra" de um cantador, o agudo do "tiple" das folias. Tudo isso tem que se transformar em matéria de conversa e reflexão, sob pena de ignorar-se a curiosidade dos estudantes. $^{3}$ O silêncio apenas reforçaria a percepção "classecêntrica" da qualidade vocal dos intérpretes.

Mas o que se pode dizer sobre essas vozes? Por que nosso vocabulário soa limitado, ingênuo e amador? Os membros da comunidade acadêmica estão habituados a terminologias controladas e uniformes. A metáfora é considerada último recurso, embora seu uso seja freqüente entre músicos. ${ }^{4} \mathrm{~A}$ consulta à literatura dos folcloristas não ajuda muito, nesse caso da voz. Veja-se o que disse Alceu Maynard de Araújo, por exemplo, num texto sobre o jongo em Taubaté, após (surpreendentemente) admitir que "é admirável o senso musical dos jongueiros": "Quando estão dançando, todos os jongueiros cantam, fazendo coro. E é bem difícil tentar dançar com uma negra de voz esganiçada e estridente. cada vez que ela se aproxima da gente, dói-nos o ouvido." (1952, p. 206). Câmara Cascudo (1984 [1942]), na mesma época (meados do século XX), descreveu assim a voz do cantador nordestino: "dura, hirta, sem maleabilidade, sem

\footnotetext{
${ }^{2}$ Chamo "folclórica" à música cujos circuitos de produção e difusão independem do mercado.

${ }^{3}$ Tiple é o nome dado à voz mais aguda do conjunto vocal das folias de reis. no Sudeste (o termo tem origem, possivelmente, em trip/um, termo da polifonia européia medieval). V. Reily (2003).

${ }^{4}$ São muitos os autores que reconhecem a riqueza da linguagem metafórica dos músicos, em contraste com a parcimônia do vocabulário musicológico para falar da voz. V.. entre outros, Feld, Porcello, Fox e Samuels (2004).
} 
floreios, sem suavidade" e despertou reação imediata de Mário de Andrade, um atento etnógrafo da voz:

Embora ele [Cascudo] conheça dez vezes mais o assunto que eu, não creio que tenha muita razão, pois pude escutar numerosos cantadores no Nordeste e nada percebi de "voz dura, hirta, sem maleabilidade, sem floreios, sem suavidade", nem várias outras expressōes com que o meu amigo potiguar xingou os cantadores em geral. (Andrade, 1993 [1944], p. 86).

Voltarei, adiante, à preocupação de Mário de Andrade com o canto e com a voz, mas já sabemos que este autor não representa a regra - é, sim, a exceção. De qualquer modo, não é possível dedicar este artigo à revisão de sua imensa contribuição ao assunto, a qual, por ter sido marcada pelo problema da "nacionalização" do canto erudito, e interrompida com sua morte, não pode ser agora incorporada sem revisão crítica.

Como falar dos modos de cantar de repentistas, jongueiros, sambistas? Não são eles componentes do sentido e do sentimento do canto? Até onde é possivel avançar na descrição do repente, por exemplo, sem entrar no terreno do estilo vocal para integrá-lo à análise? Tem a voz cantada uma força ilocucionária 18 sui generis (Zumthor, 1997)? Que a voz individual tem uma fisionomia própria ninguém discute. São as "idiossincrasias sociais" que desejamos destacar, aquilo que varia

não simplesmente com os indivíduos e suas imitações mas, sobretudo, com as sociedades, as educaçōes, as conveniências e as modas, com os prestígios. É preciso ver técnicas e a obra da razão prática coletiva e individual ali onde de ordinário vêem-se apenas a alma e suas faculdades de repetição. (Mauss, 1974 [1905], p. 214)

Mas enquanto a matriz geradora do timbre pessoal da voz é a diferença anatômica entre os órgãos fonadores dos indivíduos (tamanho e densidade das 
pregas vocais, comprimento e área do trato vocal etc.), ${ }^{5}$ as "idiossincrasias sociais" ainda são pouco explicadas. ${ }^{6}$

Cantores e professores de canto não têm carência de vocabulário técnico, mas não há consenso entre eles e os termos que usam para qualificar as vozes e o modo de cantar não são unânimes. As categorias verbais consagradas no discurso musicológico, por sua vez, compõem um catálogo limitado, estreitamente vinculado à ópera. Não é de se estranhar, pois a história do canto na Europa e a instituição do belcanto não podem ser compreendidas isoladamente da evolução do teatro musical. Mas o vocabulário técnico que o canto "erudito" gerou é parte mesma da normatização técnica e estética que ele implica. ${ }^{7}$ Aplicar suas categorias a outros tipos de canto e vocalização é menos ingênuo do que realmente complicado: seria preciso, a cada passo, fazer a arqueologia das noções, compreender os valores aos quais estão atadas, e só então dotá-las, talvez, de outros significados. ${ }^{8}$ Dizer que uma jongueira tem voz de contralto não comunica muita coisa importante sobre sua voz, não obstante cheia de "idiossincrasias sociais"; a prova disso é que, ao tentarmos cantar como ela. beiramos a caricatura.

\footnotetext{
${ }^{5}$ V. Leite, Y. e Callou. D. (1990, p. 20): "O tamanho e a espessura das cordas vocais, juntamente com outros determinantes anatômicos, tais como o tamanho da língua, forma e altura do palato, comprimento da distância entre a laringe e os lábios, são responsáveis pela caracterização individual da voz, distinguindo a voz infantil, a masculina, a feminina."

${ }^{6}$ Essas diferenças, no caso da língua falada, são observadas pelos estudiosos de fonética. Como as formantes inferiores determinam a cor das vogais e da voz, estudos da voz cantada e fonética são aliados naturais. V. Sundberg (1987, p. 21): "The timbral properties of a note (regarding both vowel quality and voice color) depend on the frequencies at which there are strong and weak partials. In vowel sounds, this depends on the formant frequencies." V. também Risset e Wessel (1991).
}

7 As expressōes "canto erudito" e "lírico" são imprecisas, mas úteis quando se deseja agrupar a maioria dos repertórios referidos nas obras musicológicas. O termo belcanto, igualmente vago, começou a ser usado no século XIX para designar o estilo italiano elegante e leve, num momento em que já se impunha, no terreno da ópera, a sonoridade densa e intensa que os autores relacionam com o aumento do número de instrumentos nas orquestras e crescimento espacial das salas de concerto e teatros (Jander , 1980, p. 420; Jander et al., 2001).

${ }^{8} \mathrm{~V}$. Piccolo (2006) sobre as especificidades do canto popular e o desenvolvimento de terminologia adequada. 
As obras de referência musicológicas não preenchem as lacunas às quais me refiro. Uma primeira constatação impõe-se, então. Quando se trata da voz e da voz cantada, a musicologia recorre à anatomia e fisiologia dos órgãos da fonação - que são da ordem da natureza e do universal - ou às artes do canto propriamente ditas - da ordem do artifício e do aprendizado. Estas últimas, que dispõem de um vasto acervo de técnicas desenvolvidas para o treinamento de cantores, são eminentemente práticas. O vocabulário por elas desenvolvido não pode ser dissociado da experimentação direta, corporal, nem das normas de um universo musical particular. Parece, em suma, que a musicologia propriamente dita dá a palavra ora aos anatomistas, ora aos cantores.

Kerman (1987), por exemplo, em seu balanço crítico da musicologia anglo-americana, não fala do canto. Observações muito breves do autor indicam que foi a chamada "performance histórica" - a execução de música barroca e renascentista, basicamente - que suscitou tentativas de libertar-se das constrições do belcanto a partir do estudo de tradições vocais mais antigas da Europa ocidental. Canto sem vibrato e agudos "estridentes" cuja realização sonora era sugerida pela audição de populações não-ocidentais passaram a integrar o elenco de técnicas capazes de conferir a controvertida autenticidade histórica. ${ }^{9}$

Ele ajuda a nos lembrarmos, com essa observação en passant, que não se trata de opor dois padrões hegemônicos de canto (o culto e o popular comercial) às variedades folclóricas, pois tanto no nível erudito como no comercial vigoram. hoje, mais de um padrão. O canto erudito rompeu, ao longo do século XX, com as balizas herdadas da era romântica; o mercado compartimentado abriga, entre a balada e o blues, o heavy metale o rap, considerável diversidade. Apesar disso, as obras de referência musicológica mantêm o foco nos apanhados da história dessas classificações, a partir da Idade Média. Os autores do verbete "Canto"

\footnotetext{
${ }^{9}$ V. Kerman, J (1987, p. 291): "Muito se tem especulado acerca do canto sem vibrato, ou com vibrato de um tipo muito diferente do que se ouve no moderno teatro de ópera (ou, a bem dizer, na moderna capela de Oxbridge). Tal modalidade de canto pode ser ouvida em tradições musicais não-ocidentais, mas na performance de música ocidental só a principal cantora de Morrow, Jantina Noorman [...] parecia capaz de executá-lo de modo convincente. Os agudos estridentes de Jantina, suspeita-se, são o modo como a performance de música mais antiga tem de ser realizada [...]".
} 
(Singing) da última edição do New Grove (Jander et al., 2001) assinalam a efemeridade da voz e a impossibilidade de se inscrever sua qualidade em suportes materiais antes do advento da gravação sonora. Expandem um pouco a pequena parte dedicada ao canto popular, que já aparecera na edição de 1980 . mas não mencionam nenhuma articulação com a etnomusicologia e outras disciplinas interessadas na voz humana.

Nas enciclopédias e dicionários musicais, ${ }^{10}$ as vozes são classificadas, em primeiro lugar, por gênero (lembram alguns autores que se trata de um traço sexual secundário). Em seguida, pela região que ocupam na escala de alturas, cada uma identificada por seu âmbito, compreendido entre uma nota grave e outra aguda. Isso caracteriza seu "âmbito", "extensão", "tessitura" ou "registro", pois a terminologia varia e apresenta um problema de inconsistência, na opinião de alguns estudiosos (v. Sundberg. 1987; Laver, 1980; Davini, 2006).

São reconhecidas seis ou oito extensões que se superpõem parcialmente, masculinas e femininas - indicadas geralmente num pentagrama (e não por meio de frequências medidas em $\mathrm{Hz}$, o que é bem mais raro, como para nos lembrar da natureza eminentemente cultural dessas subdivisões do contínuo sonoro). Seu núcleo é o quarteto soprano/alto/tenor/baixo, mais as vozes intermediárias de mezzo-soprano e barítono, acrescidas, segundo alguns autores, de contra-tenor e barítono-baixo. O quarteto SATB tem origem na polifonia sacra do século XVI, ela mesma inscrita em um processo complexo que se iniciou quatro séculos antes. com o discantus medieval. Seus desdobramentos em seis ou oito vozes remontam ao século XVIII, já em conexão com a ópera (Jander et al., 2001: Randel, 1978). A taxonomia vocal vigente instala-se, portanto, no mesmo movimento que consagra um conjunto de gêneros com características e funções precisas, cultivados em instituições com poder normatizador.

\footnotetext{
10 The New Grove Dictionary of Music and Musicians (1980 e 2001). o Harvard Concise Dictionary of Music (Randel, 1978). Enciclopedia Salvat de la Musica (1967). The New Oxford Companion to Music (Arnold, 1983). Dictionnaire de la Musique (Vignal, 1990). Dictionnaire de Musique (Riemann, 1931). Encyclopédie de la Musique et Dictionnaire du Conservatoire (Lavignac; La Laurencie, 1926).
} 
A "passagem" ou mudança de registro dentro de cada uma das vozes do quarteto é um item de preocupação estética no canto lírico e no popular. Trata-se da região em que a voz dita de peito mistura-se à voz dita de cabeça ou falsete. Nas vozes femininas, fala-se ainda da voz frontal, na região mais aguda do registro de cabeça (mulheres).

Alguns autores descem ao terceiro nível hierárquico de classificação, no qual o âmbito se embaraça com critérios que aludem à qualidade da voz e, simultaneamente, ao caráter das personagens operísticas que lhes são associadas. Nesse terceiro nível hierárquico, fala-se de tipos como soprano dramático, que tem "voz potente e habilidade histriônica e declamatória acentuada"; soprano lírico, "mais leve e [com] estilo cantabile agradável"; Heldentenor ou tenor heróico, que combina "agilidade, timbre brilhante e poder expressivo" (Randel, 1978, p. 552). As tipologias acionam, pois, critérios de âmbito, especializações em determinados repertórios e personagens, e mesmo a situação institucional do artista (prima dona, por exemplo) (Vignal, 1990).

A noção de registro, tão importante para cantores e professores de canto, é tratada com bastante cuidado pelos estudiosos da voz e especialistas em fonética (embora sua existência não seja negada enquanto fenômeno perceptivo).

22 sundberg considera a noção algo confusa (somewhat hazy) porque ligada simultaneamente à altura, à intensidade e a traços tímbricos (1987, p. 49). Adota, por isso, uma definição totalmente referida à percepção: "[...] um âmbito de freqüência de fonação no qual todos os sons são percebidos como sendo produzidos de modo similar e possuindo um timbre vocal semelhante", e adverte: "dever-se-ia tomar consciência de que o caos na terminologia dos registros apenas reflete uma falta lamentável de conhecimento objetivo." (p. 50).

Outra noção complexa - timbre - é invocada sistematicamente em nossos discursos sobre a voz. Mas ela está longe de ser explicativa e transfere o problema das diferenças percebidas para um "parâmetro" objetivo do som. Para reforçar a hipótese acerca da natureza fugidia da voz, aludirei, ainda que superficialmente, à problemática do timbre. 
Vejamos agora o que disse Mário de Andrade dos cantadores Chico Antônio e Odilon do Jacaré:

[...] tinham vozes inclassificáveis diante da timbração européia. Não porém como tecido. Tecidos normais. Chico Antônio de tenor, Odilon de barítono, um bocado mais extensas que a demarcação culta. Eram vozes lindas. (Andrade, 1993 [1944, p. 86-87).

"Inclassificáveis diante da timbração européia". É nas classificações que mencionei há pouco que ele pensava quando tentava caracterizar as vozes de Chico Antônio e Odilon. Por considerá-las insatisfatórias, fez como a maioria dos leigos: lançou mão das sinestesias e "anafonias" (Tagg, 2005) que estão na base de boa parte das metáforas da voz e falou dos "tons de ouro do sol" na voz de Chico Antônio, do seu timbre "clarinante" e seu "nasal caju".

É compreensível a insatisfação de Mário com as classificações. A descrição da anatomia da fonação e dos mecanismos fisiológicos da voz, nos textos de alguns dicionários e tratados de canto europeus e norte-americanos, mal esconde a norma estética subjacente. A identificação das extensões e registros vem acompanhada, em alguns casos, da exigência de suavização das passagens e homogeneização do timbre em toda a extensão; é ponto pacífico a necessidade de sustentar o som sem chevroter - é preciso aplainar a superfície da voz e afastar qualquer semelhança com as vozes de animais. ${ }^{11}$

Há pouco mencionei a aliança natural entre fonética e estudo da voz cantada. A lingüista Beatriz Raposo de Medeiros (2006) lembra, entretanto, que o desenvolvimento da fonologia, marco da lingüística moderna, representou um afastamento do som considerado como fenômeno dotado de qualidades intrínsecas na direção do som como entidade relativa, diferença produtora de contraste que permite distinguir as unidades lexicais. O som importa por oposição a outro, num sistema. A fonética ocupa-se do som da fala (ou "fone") visto sob o

\footnotetext{
"Um dos mecanismos de controle social da voz no Ocidente consiste em assimilar os desvios à animalidade e traçar, desse modo, a fronteira que "nos" separa de "outros". V., por exemplo, o ditado repetido por Henry Estienne em Précellence du langage Francois. de 1579, que durante duzentos anos foi corrente na Itália, segundo Jane Arger: "Ballant Itali; gemunt Hispani; ululant Cermani; cantant Galli" (Arger, 1926. p. 975).
} 
prisma da acústica, da articulatória e da percepção, enquanto a unidade de análise da fonologia é o fonema, o som da fala abordado quanto às "diferenças [...] intencionais, distintivas [...] que se vinculam a diferenças de significação." (Leite; Callou, 1990, p. 11). Assim, o desenvolvimento moderno da lingüística, assegurado pela perspectiva estrutural à qual se vincula o conceito de fonema, implicou na menor atenção à qualidade vocal, à voz cantada, às "idiossincrasias sociais" da vocalização em geral.

É claro que os lingüistas reconhecem o papel que desempenham, na produção de sentido da fala, as variações de altura, intensidade e duração dos sons. Mas a maioria dos fenômenos fônicos que gera contorno melódico, acentos e ritmos se situa no plano paralingüístico e prosódico. Eles "não constituem isoladamente traços pertinentes em português para a oposição entre palavras, mas possuem funções expressivas e, portanto, devem ser levados também em conta numa descrição fonológica." (Leite; Callou, 1990, p. 37). Os etnomusicólogos, porém, têm sublinhado a relevância desse plano: "A musicalidade da língua - suas qualidades tonais, tímbricas, prosódicas e dinâmicas - realça o papel da performance vocal para o significado lingüístico." (Feld et al., 2004, p. 323).

Antes, porém, de simplesmente reivindicar uma colaboração mais efetiva dos vários campos em que se repartiram os aspectos da voz e as perspectivas a partir das quais foi objetivada, é necessário rever as razões dessa pulverização do objeto. Se, por um lado, as múltiplas modalidades de vocalização - canto. fala, grito, pranto, prece etc. - propiciam a partilha disciplinar e dificultam apreensões integradas, por outro há a limitação própria da musicologia.

Tendo como objeto central obras em sua forma de textos escritos, os métodos musicológicos não oferecem recursos para analisar estilos e qualidades vócais. O historiador da música Carl Dahlhaus lembra, muito a propósito, a tensão entre duas concepções da música que atravessa o pensamento no Ocidente: a que entende a música como poiesis, i.e., como produtora de objetos destacados da atividade humana (objetos externos ao homem que permanecem quando cessa a 
atividade); e a que entende a música como praxis, ação geradora de um fluxo sonoro que se esgota quando se interrompe a atividade. Nos termos de J.G. Herder, a música é energeia (atividade) e não ergon (obra). Diferentemente das artes plásticas, cujo produto objetivado nunca foi posto em dúvida, o status de obra-de-arte da música foi conquistado, no século XVIII, como resultado de um processo em que se conjugaram os esforços dos pensadores e importantes transformaçōes sociais que culminaram na autonomização dos campos artísticos. ${ }^{12}$

É ainda Dahlhaus que lembra o papel que desempenharam na consagração do conceito de obra musical, em momentos distintos, a escrita musical (que isola textos de contextos) e o concerto burguês (que exige a escuta "estética"). É preciso acrescentar ainda a entrada da música no mercado, desprendendo das relações sociais um objeto musical que ganha equivalência em moeda (ao ser representado ou copiado) e, por último, as gravaçōes sonoras que fixaram em suportes materiais o som evanescente. Mas estas últimas observações sociológicas extrapolam o exame do pensamento estético, como faz Dahlhaus. O que interessa é o reconhecimento da tensão entre praxis e poiesis, energeia e ergon, atividade e obra. Ela lança uma luz sobre a retirada dos discursos "cantológicos" para os terrenos onde, aparentemente, eles se fixaram desde o século Xix: de um lado, o da anatomia e fisiologia, que entendem a voz como parte da natureza humana; de outro, o da normatização técnica e estética onde se exercem controles sociais sobre a voz cantada. Ora, pode-se pensar - por hipótese - que a voz é, irremediavelmente, energeia que se extingue quando reduzida seja à palavra, seja à melodia. Mas de que instrumentos dispomos para falar da voz?

Nas páginas anteriores, observei dois fenômenos simultâneos: em primeiro lugar, o caráter particular e historicamente situado das terminologias vocais desenvolvidas no âmbito do canto erudito; em segundo lugar, o alheamento recíproco entre os diversos campos de investigação da voz e do canto. O primeiro não surpreende e afeta, na verdade, todas as terminologias

\footnotetext{
${ }^{12}$ V. Dahlhaus (1988 [1971], p. 220): "In music the concept of a work arose at a relatively late stage in history, and. in contrast to the concept of the work in the visual arts has always been a precarious one. For music is directly and primarily experienced as a process or a performance, and not as a form which confronts the listener."
} 
técnicas e vocabulários conceituais. Não estou reivindicando um glossário transparente, estabilizado, presumidamente universal e imune às exigências e constrangimentos sociais que cercam a voz. Quanto ao segundo, não há solução simples para a pulverizaçāo dos discursos sobre a voz. Nesse panorama, duas aproximaçōes contrastantes destacam-se e são comentadas a seguir: a cantométrica de Alan Lomax e as etnografias da fala e da música que consideram especialmente a voz. Apesar das diferenças entre elas, todas têm como ponto de partida a percepção da correlação entre estilos vocais e categorias sociais, de tal modo que as diferenças entre os primeiros são índices de fronteiras entre as segundas; os esforços na educação e manipulação das vozes não se desvinculam da elaboração de identidades sociais, assim como da delimitação de categorias sociais, da recusa ou afirmação de pertencimento a um grupo.

\section{Cantométrica}

Toda a empresa da cantométrica assenta sobre a relação entre "traços da performance da canção e características da estrutura social" (Lomax, 1978). De modo análogo, as etnografias reiteram as "conexōes entre voz cantada, lugar. classe, etnicidade e identidade" (Feld et al., 2004, p. 321). ${ }^{13}$

Volto, mais uma vez, às vozes dos cantadores, refratárias à taxonomia do belcanto:

A voz de canto [de Chico Antônio] é magnífica, um bocado estragada já por noites inteiras de abusos. Mas nos dias em que Chico Antônio está "de voz" não é possivel a gente imaginar timbre mais agradável. Timbre nosso muito, firme. sensual, acalorado por esse jeito nasal de cantar que é uma constância de todo o povo brasileiro. Apenas Chico Antônio quintessenciou esse jeito nosso de cantar. É um nasal discreto, bem doce e mordente, um nasal caju. (Andrade, 1993 [1929]. p. 169).

\footnotetext{
13 Estudos etnomusicológicos sublinham seguidamente o caráter social da voz. V. LortatJacob (2006, p. 66): "la voix bénéficie d'une étonnante souplesse, qui lui sert, for some reason, à souligner, ou même à créer, des clivages sociaux et culturels. [...] Qu'elle soit chantée ou parlée, la voix humaine est, comme chacun sait, un puissant facteur de distinction - voir de discrimination sociale."
} 
Não que Mário estivesse pouco treinado para a escuta e descrição verbal de técnicas vocais, que ele indica com segurança no canto dos cantadores: "apoiaduras" (apoggiaturas), portamentos, ligaduras, glissandos, bocca chiusa, suspiros, parlato, humming. Estes termos que designam ornamentaçōes, modos de ataque dos sons e modalidades vocais distintas da fala e do canto atestam seu esforço analítico.

Ainda assim, persistia a carência de uma avaliação global que desse conta de traços compartilhados, do caráter "étnico" das qualidades vocais, decorrentes da estrutura fonética da língua e das tendências entoativas da fala. Há um timbre afroianque, um timbre afrobrasileiro, outro europeu. Essa foi uma das teses de Mário no Primeiro Congresso da Língua Nacional Cantada:

Mas si estes estudos [do belcanto europeu] encorpam, afirmam e desenvolvem a voz, não são eles que fazem o próprio canto. Este deriva muito mais do timbre, da dicção e de certas constâncias de entoação, que Thes dá o caráter e a beleza verdadeira. E si usamos no canto brasileiro, o timbre, a dicção e as constâncias de entoação que os fornece o belcanto europeu, o canto nacional de desnacionaliza e se perde. (Andrade. 1991 [1937], p. 97).

Retenho, dessa tentativa pioneira de abordar a diversidade dos modos de cantar, a idéia de "canto brasileiro". Mas a que realidade ela remete: à percepção empírica da existência de idiossincrasias sociais ou à postulação a priori do canto nacional? Provavelmente, há um pouco de cada uma nas preocupaçōes andradianas com o canto e a voz.

Cerca de três décadas depois, aparece nos Estados Unidos um ambicioso projeto de mapeamento global do canto popular (folk song), que seu idealizador Alan Lomax batizou "cantométrica". Seu ponto de partida assemelha-se à preocupação de Mário de Andrade:

Não existe terminologia consensual para descrever as qualidades da voz falada ou cantada, nem há ainda um corpo teórico aceito para explicar ou descrever, em termos fisiológicos ou acústicos, onde e como estas qualidades são geradas. Essa é uma área na qual professores. patologistas da 
fala, psicólogos, linguistas e laringologistas assumem perspectivas diferentes. (Lomax, 1978, p. 70).

A proposta inovadora pretendia correlacionar sistematicamente estilo vocal e "sistema cultural". O nome cantométrica traduz ao mesmo tempo o arrojo visionário e o cientificismo da análise que seccionava o canto em 37 parâmetros supostamente observáveis isoladamente uns dos outros e mensuráveis. Lomax alertou que o neologismo indicava tanto a mensuração dos traços estilísticos do canto quanto a possibilidade de tomar-se a canção como uma medida dos "padrões culturais": cantométrica significa "a measure of song or song as a measure". Para cada exemplo gravado, a análise gera uma ficha de codificação. Examinando-se, em seguida, as semelhanças entre as fichas das cançōes representativas de uma "cultura", sintetiza-se o estilo vocal daquele agrupamento humano. Por fim. cada um dos estilos vocais do globo é traduzido num algoritmo, permitindo a desejada comparação em larga escala.

As críticas à cantométrica são conhecidas na etnomusicologia: generalização com base em amostras reduzidíssimas (dez cançōes), dependência da análise da delimitação prévia de áreas culturais, rendimento questionável de procedimentos analíticos trabalhosos. As correlaçōes ousadas entre organização política, costumes sexuais pré-maritais e traços vocais (como nasalidade e aspereza) ferem a sensibilidade etnográfica característica dos estudos contemporâneos de cultura por se moverem entre planos analíticos muito afastados, sem mediaçōes e sem qualquer referência às concepçōes "nativas".

Tudo se passa como se o comparativismo dos grandes mapeamentos de áreas culturais se houvesse hibridizado com convicçōes de matiz culturalista acerca do "estilo" ou "tom" das culturas, e com preocupaçōes com a integração estrutural-funcional de todas as instâncias da cultura. Sendo o canto um "padrão aprendido", redundante e formalizado, mas incorporado e tornado inconsciente, ele aponta para o âmago da cultura: "O estilo é um classificador poderoso porque vai ao nível no qual as pessoas realmente experimentam e conformam os padrões culturais." (Lomax, 1978, p. 11-12). No nível empírico, a conexão é dada pelas 
evidências de que o estilo co-varia com padrões dos sistemas produtivo e político, com a estratificação social, coesão grupal. moral sexual etc.

Meu objetivo não é repetir as críticas ao método, com as quais estou de acordo, mas assinalar dois aspectos. Pela primeira vez, na etnomusicologia, o estilo vocal foi considerado relevante o bastante para ser tratado como fenômeno que engloba melodia e ritmo. O que quer dizer que o plano morfológico e sintático da melodia deixava de ser o centro da análise musical das canções. A aplicação do método exige que o analista focalize a audição nos seguintes fatores: grau de integração tonal e rítmica dos coros (tonal blend, rhythmical blend). ornamentação, andamento, volume, glissando, melismas, tremolo, efeitos glotais (ataques guturais), registro (enteridido como extensão), tensão, nasalidade, aspereza (raspiness), acentuação dos ataques, emissão precisa ou embaçada das consoantes.

Concebida como um método de análise dos aspectos "paramusicais", a cantométrica focaliza deliberadamente qualidades globais do canto (overall qualities) para descobrir conexões entre padrões culturais e vocais. Há outros elementos inovadores no método cuja atualidade parece fora de dúvida, já que suas implicações e limites não foram explorados. Um deles é o reconhecimento da acuidade das pessoas comuns na observação dos movimentos sutis na qualidade da fonação. Com esse argumento, Lomax justificava as mensurações "grosseiras" que solicitava dos analistas que aplicariam o método, convidados a situar numa escala de três ou cinco graus cada componente do estilo. A avaliação a ouvido nu replicaria, em tese, a que tem lugar na vida social, que dispensa a interposição de artifícios de laboratório entre a fonte sonora e o ouvinte. A grade de 37 parâmetros da cantométrica, externa às tradições analisadas, garante uma espécie de écoute éloignée que neutraliza os preconceitos estéticos do ouvinte. Talvez Lomax tenha razão quanto a isso, pois uma vez que certa qualidade vocal se torna natural para o ouvinte e passa a integrar sua expectativa de "voz modal". ele cessa de observá-la conscientemente. Entretanto, o pertencimento do ouvinte à mesma comunidade linguístico-musical do cantor ou falante é o que assegura a 
compreensão plena dos significados e afetos transmitidos pelas variaçōes na voz modal - e isso não está ao alcance da audição distanciada.

Cantométrica é um dos mais notáveis passos na direção de uma antropologia da voz. Tão impossivel quanto ignorá-lo é aplicá-lo, pois, ao mesmo tempo em que é o único método a conclamar os estudiosos a escutar a qualidade da voz, ele nos pede que derive significação dos graus que os parâmetros alcançam numa escala arbitrariamente instituída pelo analista.

Se nos ativermos à proposta de codificação do estilo, o método parecerá mais uma instância do impulso de racionalização musicológica, numa vertente radical do cientificismo que é a de quantificação - vertente de difícil aplicação a fatos pouco propícios à medida. ${ }^{14}$ Os 37 parâmetros do canto identificados por Lomax não são propriamente quantificáveis, mas a ficha de codificação prevê até 13 graus para muitos deles. A unidade tonal entre as vozes simultâneas, por exemplo (o "grau" de uníssono, diríamos), varia do nível "mais individualizado e menos integrado" ao "mais integrado". O volume das vozes vai de $p p$ a $f f$, passando por $p$. $m f$ e $f$, e assim por diante. É claro que altura, durações e intensidade podem ser medidas com escalas objetivas: as de freqüencias medidas em $\mathrm{Hz}$, de amplitude em $\mathrm{dB}$, de tempo cronometradas. Mas tanto no canto quanto na fala (e nesta ainda mais), os valores relativos e as categorizações são mais importantes para músicos e falantes do que o número absoluto de ciclos por segundo ou decibéis.

Se aspereza, falsete e outros fenômenos podem ser descritos desde os pontos de vista da acústica e da fisiologia, e representados graficamente por meio de espectogramas, ${ }^{15}$ as medidas e gráficos não autorizam nenhuma ilação sobre 0

\footnotetext{
${ }^{14}$ A distinçāo entre unidades discretas e categorias é útil neste caso. Certas qualidades não podem ser seccionadas em valores discretos; mas, no nível da percepção, podem ser distribuídas em categorias que agrupam valores objetivamente situados em pontos distintos do contínuo (v. Cadoz, 1991. p. 28-29).

${ }^{15} \mathrm{O}$ uso de programas de informática para representar o espectro das vozes sobre duas coordenadas - frequência e amplitude - pode ser uma ferramenta útil. Há, contudo. utilizaçōes ilustrativas que confirmam o que já se havia apresentado ao ouvido como dotado de alguma significaçāo (no sentido amplo da palavra). V. os gráficos da voz de Ray Charles cantando "Georgia on my mind" e as observações nāo obstante interessantes e pertinentes de B. Lortat-Jacob (2006), as quais antecedem a observação dos gráficos.
} 
fato de certa qualidade vocal ser obrigatória para determinados grupos, em certos contextos rituais e musicais, e não para outros.

A reação ao comparativismo em escala global e as premissas universalistas acerca do canto contribuíram para o abandono da cantométrica como uma ferramenta corrente dos etnomusicólogos e antropólogos. Entretanto, Folk Song Style and Culture impressiona pela riqueza dos aspectos e componentes estilísticos observados e pela convicção na necessidade de integrar o estilo vocal às análises musicais.

\section{Sobre os conceitos de qualidade vocal e de timbre}

Antes de prosseguir, faço uma pausa breve para apresentar o conceito de qualidade vocal, introduzido por estudiosos de voz e de fonética. Mais exatamente, convém saber como este conceito se relaciona com o de timbre, mais conhecido dos músicos e que vem sendo bastante discutido na musicologia e na acústica musical.

A fonética moderna caracteriza-se pela análise segmental (no nível das consoantes e vogais) e pela noção de fonema, que supōem o seccionamento do fluxo sonoro da fala em busca das unidades propriamente fonológicas; i.e., que produzem contrastes e são pertinentes no nível lexical. Há, contudo, abordagens que, sem discutir o ganho da análise segmental, procuram suplementá-la pela atenção ao contínuo, às características percebidas em níveis supra-segmentais.

A noção de qualidade vocal foi introduzida pelo lingüista $W$. Abercrombie para indicar o "colorido auditivo característico da voz de um falante individual". Trata-se de um aspecto da percepção do som cuja correspondência com os aspectos articulatório e acústico cabe aos pesquisadores averiguar. John Laver a incorpora para falar dos aspectos contínuos da fala que veiculam informação sobre as características físicas, psicológicas e sociais do falante. A extensão temporal das unidades em que se mantém uma mesma qualidade vocal varia muito - desde uma sílaba até enunciados inteiros (não há limite superior para a duração de um segmento dotado de uma dada qualidade vocal). Trata-se, 
então, de um elemento que, ao lado do conteúdo linguístico e para-lingüístico, totaliza o fenômeno da fonação.

Cada qualidade vocal identificada por Laver corresponde a uma postura articulatória (articulatory setting) ${ }^{16}$ ou seja, um ajuste muscular dos órgãos que, uma vez adotado, se mantém até que ocorra a necessidade e/ou oportunidade de mudança. Nesse momento, altera-se a qualidade da voz mediante mudança da postura. Ao contrário da abordagem estrutural fonológica, que focaliza unidades mínimas em seus contrastes com outras, nos eixos da combinação e da permutação, a descrição fonética da qualidade vocal enfatiza o contínuo e o semelhante. Cada exemplo é analisado a partir da identificação das posturas articulatórias que supõe e cujo efeito acústico gera a percepção da overall voice do falante.

As posturas articulatórias, com seus resultados sonoros, são características de grupos sociais e regionais (Laver, 1980, p. 6). Por conseguinte, certas qualidades vocais constituem aquelas "idiossincrasias sociais" que motivaram parte das buscas de Mário de Andrade, por exemplo.

Embora a noção de qualidade vocal adotada e desenvolvida por Laver pareça preencher a expectativa de analisar fenômenos perceptivos mais

32 contínuos, que podem ser tomados como um fundo contra o qual se destacam as formas das configurações "alteradas" e suas correspondentes qualidades vocais, o próprio autor opera também com a noção de "voz modal" (e sua postura correspondente, "neutra"). Em outras palavras, parece que a noção de qualidade vocal se aplica tanto às características da própria voz modal ou overall voice aquela assumida natural e espontaneamente pelo falante na conversação ordinária - quanto às características mais salientes dos desvios com relação à primeira. Do ponto de vista articulatório, a voz modal corresponde a uma postura muito próxima à do órgão fonador em repouso. A voz cantada é sempre um

16 "Broadly, it is the fundamental groundwork which pervades and to an extent determines the phonetic character and specific timbre of a language. It is immanent in all that the organs do." (Honnikan apud Laver, 1980, p. 12). 
afastamento relativo da voz modal, sendo que a do canto lírico se caracteriza, precisamente, por um afastamento bastante acentuado.

Laver prefere "qualidade vocal" a "timbre" para descrever a voz de um indivíduo ou a voz que ele produz durante um determinado tempo de fonação. Outros pesquisadores usam qualidade vocal de modo mais abrangente, para indicar "aquilo que diferencia duas produções vocais com o mesmo conteúdo lexical" e que inclui, como um de seus aspectos, o timbre espectral:17

A qualidade vocal aparece assim como uma noção muito complexa que faz intervirem aspectos de prosódia, entonação, articulação, altura, intensidade e de timbre espectral, em todos os níveis de representação da fala (Garnier et al., 2005, p. 152)

A preferência por essa idéia tem relação com o fato de ser o timbre um conceito multidimensional que não se limita à forma assumida pelos harmônicos do som fundamental. Ele inclui aspectos do ataque, do desenvolvimento temporal e extinção do som (v. Risset; Wessel, 1991; Sundberg. 1987; Aharonián, 2002).

Tem-se a impressão de que o uso da noção de timbre por leigos se aproxima mais da idéia de qualidade vocal do que propriamente da definição acústica de timbre, muito especializada. Veja-se, por exemplo, a observação etnográfica das conversas nos estúdios de gravação:

A proeminência das conversas sobre timbre na indústria fonográfica contrasta diretamente com os discursos sobre música de críticos e acadêmicos no Ocidente que enfatizam o plano das dimensōes harmônica, tonal e rítmica. Os musicólogos frequentemente caracterizam as discussōes sobre timbre como meras imitaçōes verbais ou metáforas impressionistas. (Feld et al., 2004, p. 323).

Qual a razão da reticência dos musicólogos? Talvez ela deva ser buscada na distinção, explicitada pelo musicólogo Leonard Meyer, entre parâmetros musicais "primários", que geram a ordenação sintática da música (melodia, ritmo,

\footnotetext{
${ }^{17}$ Trata-se de uma definição por exclusão, exatamente como as definições correntes de timbre - aquilo que não é altura nem duração nem intensidade de um som.
} 
harmonia), e "secundários", que não podem fazê-lo em virtude de limitaçōes cognitivas (dinâmica, timbre). Para que se efetive uma sintaxe musical, segundo Meyer, é preciso que se estabeleçam critérios de "mobilidade" e "fechamento" dos estímulos sonoros (1989, p. 14). Ou seja: se o ouvinte percebe uma sucessão de sons (por exemplo, uma sucessão ascendente de semitons ou uma sucessão de colcheias, ou um contínuo gradual de intensidades do $f$ ao $f f$ e não são dados pontos preferenciais de articulação, não há critério para a clausura e, por conseguinte, não há sintaxe possivel:

Tais critérios só podem ser estabelecidos se os elementos de um parâmetro puderem ser segmentados em relações discretas, não uniformes, de tal modo que as semelhanças e as diferenças entre elas sejam definíveis, constantes e proporcionais. (Meyer, 1989, p. 14).

Uma seqüência cromática ou uma tríade aumentada organizam os sons de modo uniforme; um glissando é um contínuo sem unidades discretas e não-uniformes: em nenhum dos dois casos há expectativa de clausura. Além disso. os meios materiais dos parâmetros secundários não podem ser segmentados em relaçōes proporcionais:

[...] não há [...] nenhuma relação, no domínio da dinâmica, que corresponda a uma terça menor ou a um ritmo pontuado. E o mesmo é verdade para andamento, sonoridade, timbre. Mas porque eles não podem ser segmentados em relações perceptivamente proporcionais, não há estados de clausura específicos para esses parâmetros secundários. É, pois, a presença de constrições sintáticas que distingue os parâmetros primários dos secundários. (Meyer, 1989, p. 14).

Repare-se que Meyer dá por entendido o conceito de timbre que se refere, em seu texto, à percepção das diferentes fontes sonoras (instrumentos musicais) e suas combinaçōes; é usado em conjunto com sonoridade (sonority). que indica (em meu entendimento) a percepção de qualidades do som tais como brilho, densidade etc. Seja como for, Meyer continua seu argumento explicando que os parâmetros secundários podem ser descritos em termos de quantidades 
mais do que em termos de relaçōes categoriais (como "antecedenteconseqüente"). Mas os exemplos que o autor dá em apoio à sua afirmação dizem respeito aos níveis de dinâmica, taxas de atividade e sonoridade, todos percebidos como situados num gradiente. Uma vez iniciado certo processo musical no qual está em jogo esse parâmetro, ele tende a continuar: "Assim, se os parâmetros primários são ditos sintáticos, os secundários podem ser rotulados estatísticos." (Meyer, 1989, p. 15). É evidente que, ao chegar a essa conclusão, o autor já se esqueceu do timbre e tem em mente apenas dinâmica e andamento. Em que sentido seriam timbre e sonority estatísticos?

A abordagem do timbre por Meyer sugere uma hipótese explicativa da dificuldade de falar seja de timbre, seja de qualidade vocal: o discurso científico sobre a música, organizado disciplinarmente no final do século XIX, tributário do processo de racionalização (Weber, 1995), desenvolveu-se a expensas das dimensões práticas da música (tais como o canto ou a performance de um modo geral, sistematicamente rebaixados na hierarquia dos ofícios musicais) e das qualidades dos materiais musicais.

Exatamente como Steven Feld e outros observaram (no artigo citado há pouco), o caso de Meyer é a sintaxe - o plano em que ocorrem os fenômenos musicais dignos de nota. ${ }^{18}$ Desejo apontar, porém, a indefiniçāo de timbre no texto de Meyer. Do ponto de vista da acústica, "timbre é o atributo da percepção que permite distinguir os instrumentos da orquestra quando tocam a mesma nota com a mesma dinâmica." (Risset; Wessel, 1991, p. 102). Atributo da percepção. o timbre está antes no sujeito que na natureza. Seus correlatos físicos são ainda objeto de investigação. Com efeito, os estudos de psicologia cognitiva testam a hipótese de ser o timbre (em geral, e não apenas o da voz) um fenômeno da percepção, portanto das representações que a informam:

Sustentar-se-á, pois, a hipótese de que a definição do timbre e a identificação das propriedades físicas que o caracterizam não são pois "intrínsecas ao sinal" mas dependentes dos quadros conceptuais dos sujeitos que o definem. (Castellengo; Dubois, 2005, p. 3).

\footnotetext{
${ }^{18}$ V. também Keil (1994).
} 
O timbre é perceptualmente "biface": identificado primeiramente pela fonte um timbre é sempre timbre de algo -, depois pelas qualidades. É, sobretudo, um atributo musical: caracteriza um objeto cultural irredutível à descrição do sinal acústico (Castellengo: Dubois, 2005, p. 3).

Mas o que significa falar do timbre da voz? Para os estudiosos de fonética e da voz cantada, a percepção do timbre está ligada à intensidade relativa dos harmônicos principais e às formantes constituintes das vogais (v. Mason, 1983, p. 1944). Se a cor vocálica e o timbre da voz estāo associados (do ponto de vista acústico), a fonética é uma "timbrística" no nível segmental. Por isso, Castellengo e Dubois (2005) preferem falar de qualidade vocal, que se revela tanto no nivel do fonema - como conteúdo espectral de um som - quanto no da palavra ou da frase - como variações espectrais ao longo do eixo do tempo. ${ }^{19}$

Disso tudo, depreende-se que a noção de timbre é acionada com desenvoltura por músicos e leigos, para identificar fontes sonoras e/ou qualidades, sem que isso signifique um exame do espectro físico, da maneira como fazem os acústicos. A noção de qualidade vocal partilha, com essa idéia leiga de timbre, o caráter de uma configuração geral - podendo englobar múltiplas dimensões. Embora as categorizaçōes e comparaçōes possam ser

36 estratégicas na percepção e discurso sobre a qualidade vocal (uma voz é mais clara que a outra, ou menos aveludada etc.), esta não se presta à medida.

\section{Etnografias da fala, antropologia vocal}

A qualidade da voz suscita outro tipo de abordagem, na contramão dos tratados de fisiologia e de acústica. Refiro-me aos trabalhos que assinalam a anterioridade da voz, da qual restaria sempre um resíduo sonoro que nāo se esgota na remissão ao significado. Destacam-se aí os escritos de Paul Zumthor que, indo além da noção de "transmissão oral" elaborada por folcloristas,

\footnotetext{
${ }^{19}$ Tal interseção entre fonética e análise da qualidade vocal foi levada em consideração por Alan Lomax, como vimos há pouco.
} 
concebe de modo positivo a oralidade, a qual expande em vocalidade, em corporalidade e, enfim, em teatralidade. A voz é a "pesada matéria", "anterior a toda diferenciação, indizibilidade apta a se revestir de linguagem." (Zumthor, 1997, p. 10-11). Ela é "indefinível", "inobjetivável". Mas isso não define um método de pesquisa empírica, tampouco nos leva a concluir que só resta renunciar à descrição verbal dos estilos vocais.

Outras possibilidades de conceber a voz emergem das pesquisas etnográficas da fala e da música. Oriunda do encontro entre preocupaçōes das ciências sociais, do folclore e da linguística - particularmente, das preocupaçōes com a linguagem em uso e com as formas expressivas da cultura -, a etnografia da fala e das artes verbais desenvolveu-se a partir dos anos 1960 nos Estados Unidos. As pesquisas empíricas focalizam populaçōes nas Américas, falantes de diversas línguas (incluindo os anglofones) (v. Bauman, 1977; e Bauman; Sherzer, 1974). Nessa vertente de investigação, os fatos da voz são vistos desde uma perspectiva sistêmica aplicada a suas diversàs modalidades: fala cotidiana, jargōes de grupos profissionais e de categorias etárias, canto, falas rituais - todo o leque de vocalizações de um grupo social é abordado como um sistema ou estrutura em que cada termo é iluminado por suas semelhanças e contrastes com os demais. Sua marca mais forte é uma conceituação de performance cuja repercussão em diversos campos, entre eles antropologia e etnomusicologia, nāo está dissociada das reivindicações de maior atenção à voz.

Relativos e particulares, as concepçōes e usos da voz revelados nas etnografias não são definidos a priori pelo analista - não há um ponto de vista absoluto de onde se possa determinar em quê e como diferem a fala e o canto, como fazem, algumas vezes, os estudiosos da voz ao afirmar que as variaçoes de altura, duração e intensidade dos sons são menores, menos estáveis e controladas na fala do que no canto, e que as variações na qualidade vocal são mais toleradas na primeira e evitadas no segundo. ${ }^{20} \mathrm{O}$ contato sistemático com outras maneiras de conceber o espectro de produçōes vocais propicia a relativização das

20 É verdade que a maioria dos estudiosos admite ser esta a regra em àlguns contextos sociolinguísticos: a variação de altura por certo é reconhecida como traço pertinente nas línguas tonais. 
categorias de apreciação da voz: "A melodia não é um meio particularmente conveniente para distinguir entre a fala, a instrução e a canção dos Suyá", adverte Seeger (1987, p. 49) em sua etnografia desta população de fala Gê do Brasil Central.

A voz é concebida, produzida e apreciada de um modo particular pelos Suyá. Eles reconhecem duas posiçōes contrastantes da laringe que geram. respectivamente, uma voz grave, com a garganta "aberta", considerada índice de masculinidade: e uma voz "apertada", com a garganta "pequena", apropriada à execução de um gênero de canções masculinas "gritadas" (denominadas akia). Nos termos de J. Laver, trata-se de duas qualidades vocais alteradas com relação à voz modal, que a "fisiologia" e a "acústica" suyá relacionam com duas posturas articulatórias, dois gêneros de canções e as relações sociais que implicam.

Cantométrica, fonética, fisiologia e acústica musical, etnografias da fala e da música estão entre os passos na direção de uma abordagem que tome a voz como fenômeno bio-psicossocial e integre som e sentido, interno e externo, nature e nurture. A idéia de que há modos de ser inscritos no corpo como automatismos inconscientes (Mauss, 1974) é crucial para os estudiosos de música. Ela abrange todo o domínio da vocalidade. A fronteira entre o corpóreo e universal, de um lado, e o cultural e particular, de outro, perde toda a nitidez. "A voz desafia todo binarismo", explicitou Paula Vilas (2006). ${ }^{21}$

Embora este texto não seja um balanço, fica claro que as buscas bibliográficas conduzem a diferentes campos de conhecimento, o que torna trabalhosa e exigente a revisão da literatura em cada um deles, os quais supõem formação especializada. O fato de o pesquisador ser ou não ele mesmo cantor também deve ser levado em conta. Esta experiência não pode ser negligenciada, pois fazer corresponder a um rótulo verbal certa qualidade vocal é um exercício básico ao qual os cantores estão habituados. Na literatura acadêmica e científica,

\footnotetext{
${ }^{21}$ A frase foi dita durante sua comunicação no Il Encontro de Estudos da Palavra Cantada.
} 
encontram-se pelo menos três grandes vertentes de abordagem da voz e do canto: descrições naturalizadoras do corpo e do som. que não se pode ignorar nem incorporar irrefletidamente; tipologias vocais válidas para o canto erudito. repletas de orientação para a prática e comprometidas com uma pedagogia vocal; estudos etnográficos da fala, do canto "popular" e "étnico". Começam a desenvolver-se, também, inventários e análises dos recursos vocais técnicos e estilísticos dos cantores populares (Piccolo, 2006). Como vimos, nas etnografias da fala e da música foram dados passos importantes para a compreensão da heterogeneidade de modos de usar a voz. Uma das maneiras de lidar com essa fragmentação é tentar colocar em diálogo as perspectivas das várias vertentes. tendo-se em mente o problema da descrição dos modos de cantar na música de tradiçāo oral, no Brasil.

\section{Referências}

ABRAHAMS, Roger D. Black talking on the streets. In: BAUMAN, R.; SHERZER, J. (Eds.). Explorations in the ethnography of speaking. London: Cambridge University Press, 1974.

AHARONIÁN, Coriún. Introducción a la música. Montevideo: Tacuabé, 2002.

ANDRADE. Mário de. Vida do cantador. Belo Horizonte: Villa Rica, 1993. (Edição crítica de Raimunda de Brito Batista. Obras de Mário de Andrade, v. 25).

- Os compositores e a língua nacional. In: Aspectos da música brasileira. Belo Horizonte: Villa Rica, 1991. p. 32-94.

ARAÚJO, Alceu Maynard de. Documentário Folclórico Paulista. São Paulo: Prefeitura Municipal; Departamento de Cultura, 1952.

ARGER, Jane. Évolution de la technique vocale depuis l'ère chrétienne. In: LAVIGNAC, Albert: LA LAURENCIE, Lionel de (Eds.). Encyclopédie de la Musique et Dictionnaire du Conservatoire. Paris. Delagrave, 1926.

ARNOLD, Denis (Ed.). The New Oxford Companion to Music. New York: Oxford University Press, 1983.

BARRIÈRE, Jean-Baptiste (Org.). Le timbre: métaphore pour la composition. Paris: Christian Bourgois / IRCAM, 1991.

BAUMAN, Richard. Verbal art as performance. Rowley: Newbury House Publishers, 1977:- 
BAUMAN, Richard: SHERZER, Joel (Eds.). Explorations in the ethnography of speaking. London: Cambridge University Press, 1974.

BOLOGNA, Corrado. Voz. In: Enciclopédia Einaudi Lisboa: Casa da Moeda, 1987. v. 11 (Oral/escrito - Argumentação). p. 58-92.

BLUM, Stephen. European musical terminology and the music of Africa. In: NETTL, B.; BOHLMAN, P. (Eds.). Comparative Musicology and Anthropology of Music. Essays on the history of Ethnomusicology. Chicago: The University of Chicago Press, 1991, p. 36.

CADOZ, Claude. Timbre et causalité. In: BARRIÈRE, Jean-Baptiste (Org.). Le timbre: métaphore pour la composition. Paris: Christian Bourgois/IRCAM, 1991. p. 17-46.

CARMO JR., José Roberto do. A voz: entre a palavra e a melodia, Tereza. Revista de Literatura Brasileira, São Paulo, n. 4/5, p. 215-227. 2003.

CASCUDO, Luís da Câmara. Vaqueiros e cantadores. Belo Horizonte: Itatiaia, 1984 [1942].

CASTELLENGO. Michèle: DUBOIS, Danièle. Timbre ou timbres? Propriété du signal, de l'instrument, ou construction cognitive? Proceedings of the Conference on Interdisciplinary Musicology. Montréal (Québec), Canada: 2005. Disponivel em: <www.oicm.umontreal.ca/cim05>. Acesso em: 23 jan. 2007.

DAHLHAUS, Carl. Music as text and work of art. In: Aesthetics of Music. Cambridge: Cambridge University Press, 1995. p. 9-15.

. On the decline of the concept of musical work. In: Schoenberg and the New Music. Cambridge: Cambridge University Press, 1987. p. 220-233.

DAVINI, Silvia. Voz e palavra - música e ato. Comunicação apresentada no II Encontro de Estudos da Palavra Cantada, Rio de Janeiro, 16 a 19 de maio de 2006 (inédito).

FELD, Steven; FOX, Aaron A.; PORCELLO, Thomas; SAMUELS, David. Vocal Anthropology: from the Music of Language to the Language of Song. In: DURANTI, Alessandro (Ed.). A Companion to Linguistic Anthropology. Oxford: Blackwell, 2004. p. 321 345.

GARNIER, Maeva et. al. Étude de la qualité vocale dans le chant lyrique. Scolia, 20, p. 151-169. 2005. Disponível em:

$<$ http://www.icp.inpg.fr/ - henrich/papers/Sco20Garnier.pdf>. Acesso em: 23 jan. 2007.

GLOVER, Jules e GLOVER. Henri. Physiologie de la voix. Ses applications. In: LAVIGNAC, A. (Ed.). Encyclopédie de la Musique et Dicionnaire du Conservatoire. Paris: Delagrave, 1926.

KEIL. Charles. Motion and feeling through music. In: FELD. Steven; KEIL, Charles. Music Grooves: essays and dialogues. Chicago: The University of Chicago Press, 1994. p. 53-76.

KERMAN, Joseph. Musicologia. São Paulo: Martins Fontes, 1987. 
JANDER, O; PLEASANTS, Henry. Singing. In: SADIE. S. (Ed.). The New Grove Dictionary of Music and Musicians. New York: Macmillan, 1980. v. 17. p. 338-346.

JANDER, O.; HARRIS. Ellen; FALLOWS, David; POTTER, John. Singing. In: SADIE, S.; TYRREL, John (Eds.). The New Grove Dictionary of Music and Musicians. 2nd edition. New York: Macmillan, 2001. p. 428-436.

LAVER, John. The phonetic description of voice quality. Cambridge: Cambridge University Press, 1980.

LAVIGNAC, Albert e LAURENCIE, Lionel de la. (Ed.). Encyclopédie de la Musique et Dicionnaire du Conservatoire. Paris: Delagrave, 1926.

LEITE, Yonne e CALLOU, Dinah. Introdução à fonética e à fonologia. Rio de Janeiro: Jorge Zahar, 1990.

LOMAX, Alan. Folk Song and Culture. New Brunswick, NJ: Transaction Books, 1978.

Social Structure and Sound Change. In: WESCOTT, Roger W. (Ed.). Language origins. Silver Spring, Md: Linstok Press, 1974. p. 203-205.

- Folk Song Style and Culture. Washington: American Association for the Advancement of Science, 1968.

LORTAT-JACOB, Bernard. L'image musicale du souvenir: Georgia on my mind de Ray Charles. L'Homme, 177-178 (Chanter, musiquer, écouter), p. 49-72, janvier /juin 2006

MASON. David. Voice. In: ARNOLD, Denis (Ed.). The New Oxford Companion to Music. New York: Oxford University Press, 1983. v. 2. p. 1939-1946.

MAUSS, Marcel. As técnicas corporais. In: Sociologia e antropologia, São Paulo: EPU/EDUSP, 1974. v. 2. p. 211-233.

MEDEIROS, Beatriz Raposo de. Em busca do som perdido: o que há entre a Linguística e a Música. In: ILARI. Beatriz (Org.). Em busca da mente musical: ensaios sobre os processos cognitivos em música: da percepção à produçāo. Curitiba: Editora UFPR, 2006. p. 189-227.

MEYER, Leonard. Style and music: theory, history and ideology. Philadelphia: University of Pennsylvania Press, 1989.

PICCOLO, Adriana. O canto popular brasileiro: uma análise acústica e interpretativa. Dissertação (Mestrado em Música) - Universidade Federal do Rio de Janeiro. 2006.

RANDEL, Don Michael. Harvard Concise Dictionary of Music. Cambridge: Harvard University Press, 1978.

REILY, Suzel A. Voices of the Magi. Enchanted journeys in Southeastern Brazil. Cambridge: Cambridge University Press, 2002.

RISSET Jean-Claude; WESSEL, David. Exploration du timbre par analyse et synthèse. In: BARRIÈRE, Jean-Baptiste (Org.). Le timbre: métaphore pour la composition. Paris: Christian Bourgois / IRCAM, 1991. p. 108-131. 
SUNDBERG, Johan. The science of singing voice. Dekalb, Illinois: Northern Illinois Press, 1987.

TAGG, Philip. Que és un musema?. In: ULHÔA, M.; OCHOA, A. M. (Eds.). Música popular na América Latina: pontos de escuta. Porto Alegre, UFRGS, 2005.

TOMLINSON, Gary. Music, anthropology, history. In: CLAYTON, M: HERBERT, T.; MIDDLETON, R. (Eds.). The cultural study of music. London: Routledge, 2003. p. $31-44$.

VILAS. Paula Cristina. Vozes entre Festas: a performance vocal, da etnografia à cena. Comunicação ao II Encontro de Estudos da Palavra Cantada, Rio de Janeiro, 16 a 19 de maio de 2006.

VOIX. In: VIGNAL, Marc (Ed.). Dictionnaire de la Musique. Paris: Larousse, 1990.

VOZ. In: Enciclopédia Salvat de la Música. Barcelona: Salvat, 1967. vol. 4. p. 526-534.

WEBER, Max. Fundamentos racionais e sociológicos da música. Trad., introd. e notas de L. Waizbort e prefácio de G. Cohn. São Paulo: EDUSP, 1995.

ZUMTHOR, Paul. A letra e a voz. São Paulo: Companhia das Letras, 2001. . Introducão à poesia oral. São Paulo: HUCITEC; EDUC, 1997.

42 Agradeço aos participantes do 11 Encontro de Estudos da Palavra Cantada (Rio de Janeiro, maio de 2006) e do III Simpósio de Música (SIMPEMUS) da Universidade Federal do Paraná, bem como à Comissão Organizadora deste evento e, especialmente, ao Professor Rogério Budasz. As idéias aqui apresentadas vêm sendo desenvolvidas no Projeto de Pesquisa $O$ moderno gosto das raízes, que coordeno na Universidade Federal do Estado do Rio de Janeiro (com apoio do $\mathrm{CNPQ}$ ). Sou grata a ambas as instituiçōes. Agradeço à colega Professora Ingrid Barancosky e às cantoras Luiza Borges Cardoso de Oliveira (Bolsista $\mathrm{PIBIC/CNPQ}$ ) e Adriana Piccolo (Mestre em Música pela UFRJ) as sugestōes e contribuiçōes bibliográficas. A Professora Yonne de Freitas Leite gentilmente leu as passagens que se referem à fonética, o que não me isenta da responsabilidade pelos eventuais erros cometidos.

Elizabeth Travassos: etravas@alternex.com.br

Artigo recebido e aprovado em 09 de maio de 2007 